\title{
Quantifying Juvenile Salmon Prey Quality and Exploring Trophic Linkages in Puget Sound, WA, USA
}

\author{
Amanda K. Winans ${ }^{1}$, BethEILee Herrmann', Minna Hiltunen ${ }^{2}$, Ursula Strandberg ${ }^{3}$, Michael Brett ${ }^{1}$, and Julie \\ E. Keister ${ }^{1}$
}

\author{
${ }^{1}$ School of Oceanography, University of Washington, Seattle, WA 98195, USA \\ ${ }^{2}$ University of Jyväskylä, Jyväskylä, Finland \\ ${ }^{3}$ University of Eastern Finland, Joensuu, Finland
}

Keywords: zooplankton, juvenile salmon, prey quality, essential fatty acids, Puget Sound

Prey composition and quality are critically important to the growth of juvenile salmon and to their survival to adulthood. Juvenile fish need more than just sufficient caloric intake - they also need to have a balanced composition of essential nutrients to achieve high growth rates. Eicosapentaenoic acid (EPA, 20:5 03 ) and docosahexaenoic acid (DHA, 22:6ஸ3) are essential fatty acids (EFA) needed for fish well-being and growth that must be acquired through diet (Bell et al. 1997; Glencross 2009; Daly et al. 2010). High growth rates in the early marine period of a juvenile salmon may be critical to future survival (Beamish et al. 2004; Cross et al. 2009; Duffy and Beauchamp 2011). Puget Sound serves as an important nursery area for juveniles to feed and grow for several weeks to months before migrating to the ocean, but little is known about the fatty acid content and composition, and therefore quality as prey, of the zooplankton. The goal of this project was to gain insight into the lower trophic level food web that supports salmon growth by addressing these main objectives: 1) Assess dietary quality of juvenile salmon prey taxa in Puget Sound and adjoining waters; 2) Assess spatial variability in availability of essential fatty acids (EFAs) across Puget Sound basins; 3 ) Assess temporal variability across seasons in availability of EFAs.

Zooplankton samples were collected from March through October 2017 in seven different basins of Puget Sound and adjoining waters. Samples to quantify zooplankton biomass were collected biweekly from the upper 30 $\mathrm{m}$ of the water column, where juvenile salmon feed during the daytime, using oblique tows of $60 \mathrm{~cm}$ diameter, 335 $\mu \mathrm{m}$ mesh bongo nets. Samples were preserved, quantified, identified, and life-staged or measured. Individual carbon (C) biomass was estimated from lengths or life stages using calculations from the literature. Each taxonspecific $\mathrm{C}$ biomass was multiplied by its density in the sample to estimate biomass at each site. Samples for fatty acid analyses were collected opportunistically in deeper tows (usually $>30 \mathrm{~m}$ ). Organisms were kept chilled and alive while they were sorted by species and size, quickly dipped in tap water to remove salt, then frozen in $-80^{\circ} \mathrm{C}$ until further analysis. Forty-five different fatty acids were quantified. The taxon-specific EPA+DHA content $(\mu \mathrm{g}$ FA mg $\cdot C^{-1}$ ) was multiplied by the biomass of each taxon, at each station in each month, to estimate site-specific monthly "EFA availability" to predators.

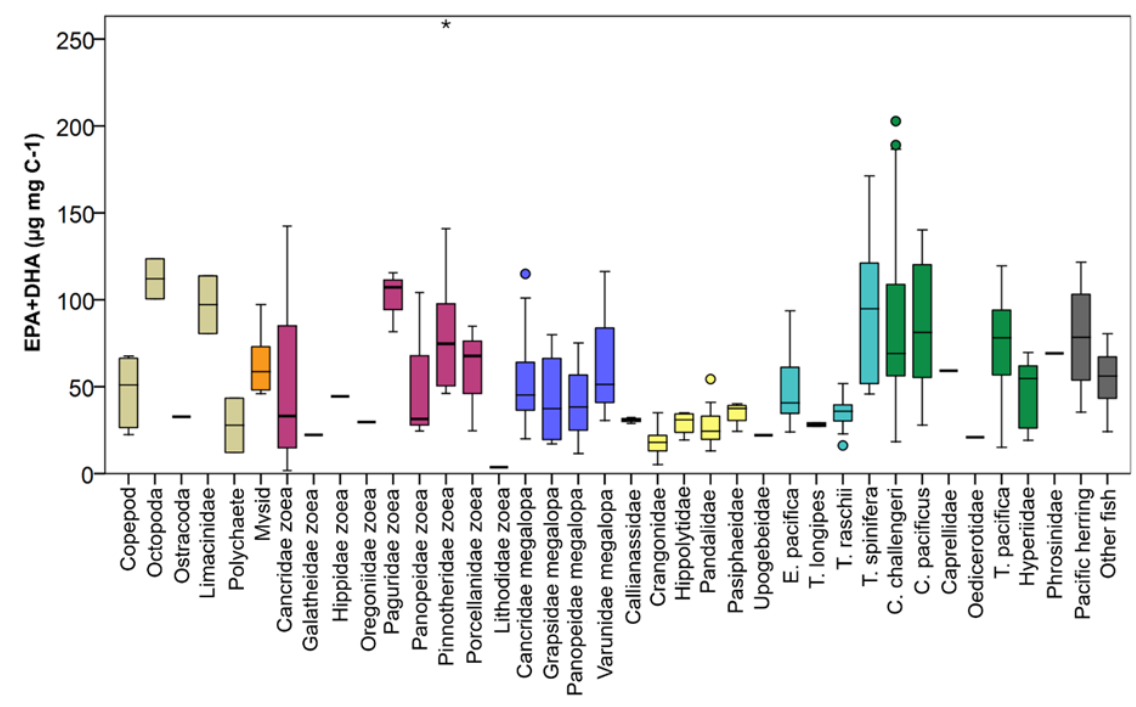

Fig. 1. EPA + DHA content of juvenile salmon prey from samples collected in Puget Sound and surrounding waters in 2017. 
Broad taxonomic groups differed in fatty acid \% composition. Amphipods, mysids, crab larvae, krill (euphausiids), and larval fish were found to be a good source of EPA and DHA, while shrimp and copepods were slightly inferior sources of EFA (Fig. 1). Some biomarkers for diatoms (16:1 $\omega 7 \& 16: 3 \omega 4)$ were dominant drivers of separation in Non-metric Multidimensional Scaling ordination. The timing and magnitude of peak availability of EPA and DHA varied among basins. Bellingham Bay had the highest availability of EPA and DHA in our data, suggesting good offshore feeding conditions for hatchery stocks of Nooksack River Chinook salmon entering Bellingham Bay. Conversely, stations in South Sound had very low EPA+DHA availability in the spring of 2017, suggesting that hatchery origin salmon juveniles from the Nisqually River that moved offshore early may have experienced poor feeding conditions. Overall, EFA availability was observed as: 1) high in Bellingham Bay in the spring and summer, 2) increasing from the spring to summer in N. Whidbey Basin, 3) decreasing from the spring to summer in N. Hood Canal, and 4) low in South Sound and San Juan Islands in the spring, and increasing in summer.

In conclusion, EFA composition in salmon prey items varies among taxa. Hyperiid and gammarid amphipods were the highest quality prey items, followed by mysids, crab larvae, krill, and fish. The quality of copepods and shrimp was markedly lower. Chinook salmon juveniles negatively select for larval stages of the bay ghost shrimp (Neotrypaea californiensis) and small copepods (Schabetsberger et al. 2003). Thus, it seems that salmon may select good quality diet items, but whether the selection is based on the food quality and is not coincidental remains to be explored in controlled feeding trials. Future studies will reveal the potential value of EFA availability in explaining temporal and spatial variation in juvenile salmon performance.

\section{REFERENCES}

Beamish, R., C. Mahnken, C., and C. Neville. 2004. Evidence that reduced early marine growth is associated with lower marine survival of coho salmon. Trans. Am. Fish. Soc. 133: 26-33.

Bell, J.G., D.R. Tocher, B.M. Farndale, D.I. Cox, R.W. McKinney, and J.R. Sargent. 1997. The effect of dietary lipid on polyunsaturated fatty acid metabolism in Atlantic salmon (Salmo salar) undergoing parr-smolt transformation. Lipids. 32: 515-525.

Cross, A.D., D.A. Beauchamp, J.H. Moss, and K.W. Myers. 2009. Interannual variability in early marine growth, size-selective mortality, and marine survival for Prince William Sound pink salmon. Mar. and Coast. Fish. 1: 57-70.

Daly, E.A., C.E. Benkwitt, R.D. Brodeur, M.N. Litz, and L.A. Copeman. 2010. Fatty acid profiles of juvenile salmon indicate prey selection strategies in coastal marine waters. Mar. Biol. 157: 1975-1987.

Duffy, E.J., and D.A. Beauchamp. 2011. Rapid growth in the early marine period improves the marine survival of Chinook salmon (Oncorhynchus tshawytscha) in Puget Sound, Washington. Can. J. Fish. Aquat. Sci. 68: 232240.

Glencross, B.D. 2009. Exploring the nutritional demand for essential fatty acids by aquaculture species. Rev. in Aquacult. 1: 71-124.

Schabetsberger, R., C.A. Morgan, R.D. Brodeur, C.L Potts, W.T. Peterson, and R.L Emmett. 2003. Prey selectivity and diel feeding chronology of juvenile chinook (Oncorhynchus tshawytscha) and coho (O. kisutch) salmon in the Columbia River plume. Fish. Oceanogr. 12: 523-540. 